\title{
Hydrodynamic investigation of fluvial sediment transport with Soil Protrusion Apparatus (SPA)
}

\begin{abstract}
In order to understand sediment transport process based on knowledge of their soil properties and hydrodynamic behaviour a series of 2D laboratory controlled small-scale experiments were conducted using the Ahlborn sediment mobile bed tank $(4.0 \times 0.6 \times 0.2 \mathrm{~m})$. Experiments were conducted in smooth and rough bed conditions with purposely-built Soil Protrusion Apparatus (SPA) to measure the basic parameters on which erosion depends. Sediment deposition patterns in equilibrium stage associated with different bed roughness and particle size distributions were fundamentally investigated. Extended physical modelling of crescent zones also included analysing their grain size distribution. Dimensional analysis and multiple linear regression methods were employed to derive a simple empirical relationship for erosion rate (ER) in terms of the shear stress $\left(\tau_{s}\right)$, average grain diameter $\left(\mathrm{d}_{50}\right)$ and soil protrusion $(\mathrm{z})$ for smooth and rough sediment bed conditions. These analyses also suggest ways to refine empirical models, examining transport rates to explore the limits of erosion and deposition influences in shallow flow conditions.
\end{abstract}

Keywords: Small-scale experiments; Smooth and rough sediment bed conditions; Deposition patterns; Dimensional analysis; Empirical relationship.

DOI 10.1515/eng-2015-0001

Received May 9, 2014; accepted August 26, 2014

\footnotetext{
*Corresponding Author: Sarik Salim: PhD Candidate, School of Civil, Environmental and Mining Engineering, University of Western Australia, 35 Stirling Highway, Crawley, Perth, WA 6009, Australia. Tel.:+61 (0) 44977 1418, E-mail: sarik.salim@research.uwa.edu.au. Formerly, MSc Student, School of Architecture, Computing and Engineering, University of East London, Docklands Campus, 4-6 University Way, London E16 2RD, UK

Ravindra Jayaratne: Senior Lecturer in Civil Engineering, School of Architecture, Computing and Engineering, University of East London, Docklands Campus, 4-6 University Way, London E16 2RD, UK. Tel.: +44 (0)208 223 2536, fax: +44 (0)208 223 2963, E-mail: r.jayaratne@uel.ac.uk.
}

\section{Introduction}

Over the last century, many researchers around the world precisely established that sediment transport in soil bed cannot be understood without investigating the interactions of different sediment sizes and its behaviour under soil-water interaction. Transport of sediment depends not only on hydrodynamic conditions but also on the sediment bed roughness and its deposition patterns. Although the physics underlying the bedload transport of sediment mixtures has received attention for long, there remains an inadequate attention to many cases. For an example, considerable work has been done to determine what controls bedload transport capacity from flume experiments [e.g. [1-3]] but very few focused on how bed roughness and grain sizes vary in response to the variation of sediment supply [e.g. [4, 5]] and how vertical grain interchange among bed surface and bedload happens during sediment movement [6].

This paper is an extension to the previous research work carried out in fluvial environment to investigate the hydrodynamic properties and empirical relationships of different soil samples in smooth and rough bed conditions. Previously, the soil-hydrodynamic interaction; sediment deposition patterns; longitudinal/lateral spreading length/area; and fluvial bed profiles for five different soil samples $\left(\mathrm{d}_{50}=0.15,0.26,0.30,0.75\right.$ and $\left.2.40 \mathrm{~mm}\right)$ were investigated [7-9]. Prominently, sediment transport research in this paper aimed to qualitatively understand the deposition patterns in equilibrium stages comparing both smooth and rough sediment bed conditions and particle size distributions. The transport capacity models developed and calibrated in this study was designed to provide simplified empirical relationships which underpins the key factors controlling sediment transport in shallow flow. It is noteworthy to advice in advance that the general goal of this paper is to derivate the erosion equations considering river morphodynamics in fluvial environment only, therefore no applications were pursued largely. 


\section{Background}

\subsection{Mode of Sediment Transport}

Sediments are transported in natural flows as bedload, in suspension, or as wash load depending on the size of the bed particles and the flow condition. The bed load is the part of the total load which is travelling immediately above the bed by rolling, sliding, or saltating and is supported by hydrodynamic forces [10]. The suspended load, on the other hand, is the part of the load which is primarily supported by the fluid turbulence [11]. Thus, bedload includes mainly sediment transport for soil grains on plane beds, although both types of transport can occur together and the limit is not always easy to define. Bedload measurement is particularly challenging due to its variability both spatially and temporally. In a series of articles, van Rijn [12-14] conducted detailed analyses on bedload transport of large-grained non-cohesive sediments of uniform shape, size, and density to quantify the parameters describing bedload movement. Despite similar efforts including other researchers, understanding bedload transport in relation to deposition patterns in different roughness remained unattended. Current research work is mainly focused on such investigations which can lead to better assessment of sediment transport study.

\subsection{Erosion Mechanism of Soils}

Soil erosion is a sporadic process that occurs through a variety of mechanisms. This process is highly dependent on the shear stress developed by the flowing water at the bed. Indeed, at that interaction the flow is tangential to the soil surface regardless of the flow condition above it; very little water if any flows perpendicular to the interface. Figure 1 shows a sample sliding mechanism assuming that the soil particle is sphere and the resultant forces are exerted by the water on the soil particle. The electromagnetic and electrostatic forces between particles are neglected because the analysis is carried out for sand or gravel particle.

Assuming the resultant force exerted by the water on the soil particle is shear force parallel to the eroding surface, the critical shear stress $\left(\tau_{c}\right)$ for the initiation of sediment motion can be written as [15],

$$
\tau_{c}=\left(W / A_{e}\right) \tan \varphi
$$

where, $W$ is the submerged weight of the particle, $A_{e}$ is the effective area of the sand particle over the shear stress ap- plied, $\varphi$ is the friction angle between two particles and $\beta$ is the particle contact angle.

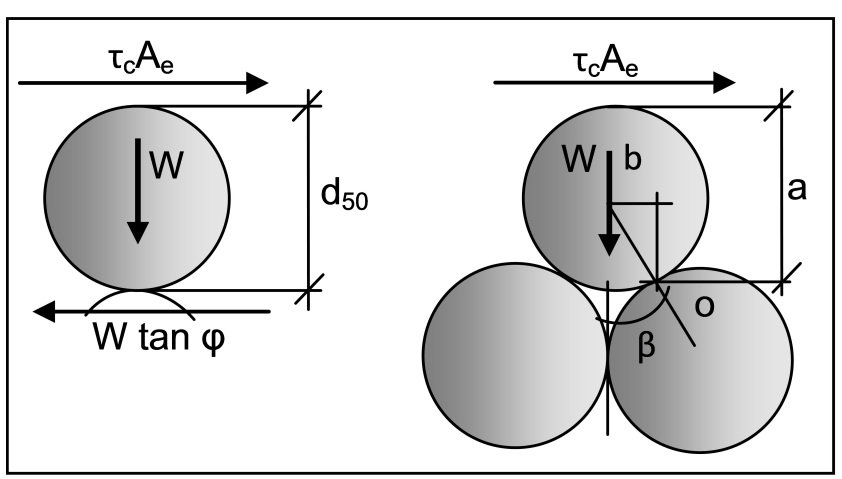

Figure 1: Force applied to soil grain during erosion [2].

Briaud [2] observed sediment movement using the Erosion Function Apparatus (EFA) for sand and gravel beds where critical shear stress is linearly proportional to the average grain diameter as given in Eq. 2. Further, he confirmed that the sliding mechanism was not the only eroding mechanism, or not the only mechanism involved. However, it was observed that the soil grains erode particle by particle method and evidence was due to the unclear of water during his experiments.

$$
\tau_{c}\left(N / m^{2}\right) \approx d_{50}(m m)
$$

Shear stress applied by the water to the bed is one of the major parameters causing erosion. After comparing shear stress $\left(\tau_{s}\right)$ values obtained from various methods, it was proposed to calculate $\tau_{s}$ in this study using the Moody diagram [16]. Therefore, the average shear stress can be written as,

$$
\tau_{s}=1 / 8\left(f \rho V^{2}\right)
$$

where, $\mathrm{f}$ is the friction factor obtained from Moody diagram, $\rho$ is the density of water and $V$ is the mean flow velocity in the pipe.

To calculate the frictional head loss of non-circular pipes the method must be adapted to use the Hydraulic Diameter instead of the internal dimensions of the pipe.

Friction factor, $f$ is a function of:

$$
f=\left[\frac{V D}{v}, \frac{\varepsilon}{D}\right]
$$

Where, $\mathrm{D}$ is the hydraulic diameter $[=2 \mathrm{ab} /(\mathrm{a}+\mathrm{b})]$, $\mathrm{a}$ and $\mathrm{b}$ are dimensions of rectangular tank, $v$ is the kinematic viscosity of water, $\varepsilon$ is hydraulic roughness $\left(=\mathrm{D}_{50} / 2\right)$. 


\subsection{Previous Development of Erosion Apparatus}

Sediment transport is often difficult to be studied without proper knowledge of measuring instruments. The accuracy of the data is strongly related to the type of instruments applied. Previously, considerable work has been done to measure the transport of sediments. Straight flumes were the earliest devices to quantify sediment transport and generally have been used to measure the bedload of relatively coarse grained and non-cohesive particles. The detail description of these devices and their applications can be found in the literature $[17,18]$. Most recently, many other apparatus have been developed primarily to measure sediment erosion. The devices of these types can be named as the Sedflume, the ASSET flume and Erosion Function Apparatus etc [1-3].

In particular, laboratory tests to determine erosion rates as a function of bulk properties were done by means of Sedflume. It was essentially a straight flume with a test section and an open bottom through where a coring tube containing sediment could be inserted. By means of Sedflume, erosion rates could be measured in the laboratory and field at high shear stresses. It had been used to measure erosion rates of relatively undisturbed sediments in the field [1]. In contrast, the Sedflume measures pure erosion that is scour of bed sediment into suspended load and bed load and subsequent transport of these loads downstream with negligible possibility of deposition in the test section.

The erosion and transport of non-cohesive sediment were observed using ASSET flume at Sandia National Laboratories, USA. The data collected from the ASSET flume were used to formulate an empirical relationship for predicting the ratio of bedload to suspended load as a function of shear stress and grain diameter for non-cohesive sediments [3].

Briaud [2] developed the Erosion Function Apparatus (EFA) to measure the erosion rate of fine and coarse grain soils. In this apparatus the end of a Shelby tube sample from the bridge site is fitted through a tight opening at the bottom of a pipe with a rectangular cross section. The water flows through the pipe and erodes the soil sample, which protrudes $1.0 \mathrm{~mm}$ above the bottom of the pipe. The rate at which the sample erodes is measured, and the shear stress imposed by the water on the soil is calculated. The plot of erosion rate versus shear stress was the result of the EFA test.

Crowley [19] introduced the sediment erosion rate flume (SERF) device to measure the bed material shear stress. The SERF is a rectangular circulating flume with an eroding sample section located in the centre of the rectangular portion of the flume. Unlike the manual advancement procedure of EFA (and previous devices), with the SERF, a computerised sample protrusion device is fitted to advance the sample automatically. SERF test results suggest that small deviations in sample geometry may have large effects on localized shear stresses.

Though a number of research on soil erosion has been performed, it is still remained a focal issue in scientific research and engineering practice. To perform an intensive investigation in shallow flow condition and aiming to reduce the lack of conceptual framework correlated with hydrodynamic erosion of river bed, a low cost and easy to construct flume, called Soil Protrusion Apparatus (SPA) is described in this paper. The SPA was developed at the UEL Hydraulics Laboratory with the following specific goals in mind; (1) to be able to perform erosion studies in different bed roughness, (2) to minimise sample disturbance, and (3) to analyse deposition patterns using real-time flow visualising techniques.

\section{Materials and Methods}

\subsection{Soil Protrusion Apparatus (SPA)}

The UEL laboratory testing facility was contained with a mobile bed and flow visualisation tank. During the smooth bed experiments, a constructed channel was made of plastic with flume dimensions of $4.0 \times 0.6 \times 0.2 \mathrm{~m}$ (Figure 2a). The tank was purposely re-fabricated in order to install a Soil Protrusion Apparatus (SPA) that takes 100.0 mm diameter sediment core samples (Figure $2 \mathrm{~b}$ ). The apparatus was placed at a distance of $1.5 \mathrm{~m}$ from the upstream of the flow, and along the centre line of the tank. The sample tube was fitted with a moveable piston which enabled the sample to be pushed to a protrusion $(\mathrm{z}=1.0-10.0 \mathrm{~mm})$ in $1.0 \mathrm{~mm}$ thick intervals (Figure 2c, 2d). The real-time flow visualisation system consists of SONY HD video camera was used to record each experiment for analysing in slow motion. The camera can capture 24 frames per second (Figure 2e, 2f). The analogical video clips were transferred to digitalized images.

Figure 3 shows the conceptual diagram of SPA for both smooth and rough sediment bed conditions. A thin plastic $10.0 \times 10.0 \mathrm{~mm}, \mathrm{X}-\mathrm{Y}$ grid system was attached at the bottom of the modified plastic flume to measure the sediment spreading lengths (Figure 3c, 3d). Several combinations of water depth, channel slope, particle size, and specific gravity were tested throughout the experiments (Table. 1). 


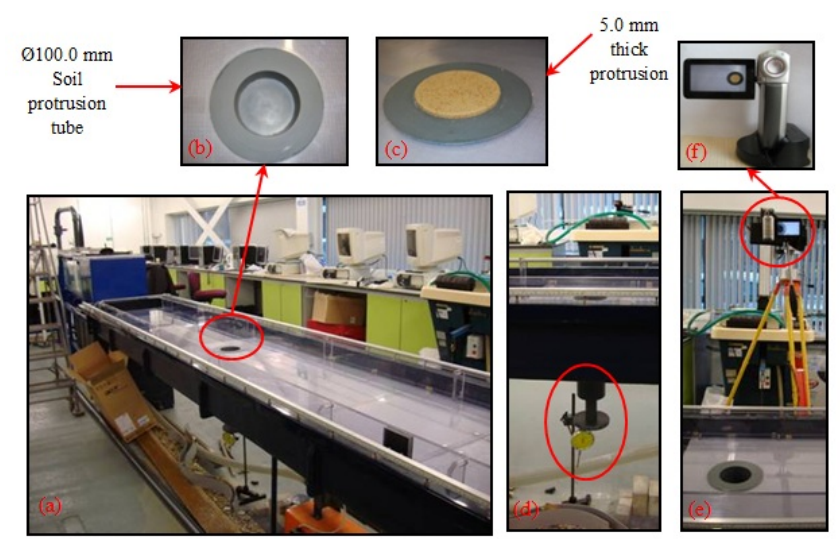

Figure 2: Modified UEL Ahlborn sediment bed tank and Soil Protrusion Apparatus (SPA) for smooth bed conditions.

The detail of the freezing process for rough bed condition is discussed in the following section.

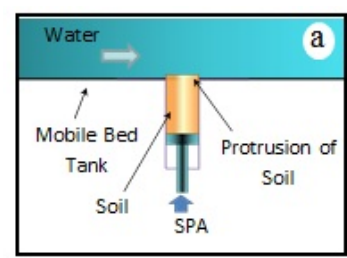

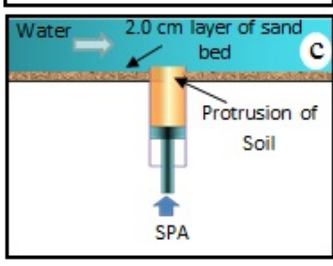

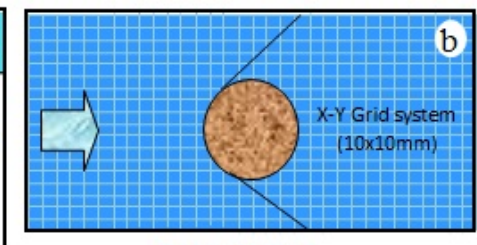

Smooth Bed

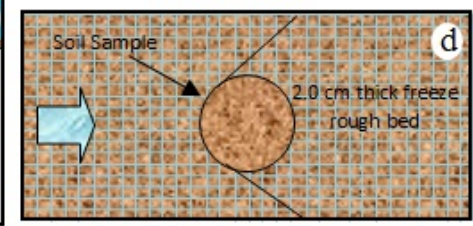

Rough Bed
Figure 3: Conceptual diagram of experimental set-up at UEL

\subsection{Preparation of Frozen Sediment Bed}

During rough bed experiments, the mobile bed plastic flume was covered with $d_{50}=0.30 \mathrm{~mm}$ sand in order to place a $2.0 \mathrm{~cm}$ thick frozen soil bed layer (Figure 4a). Figure $4 \mathrm{~b}, 4 \mathrm{c}$ shows the $100.0 \mathrm{~mm}$ diameter sample core and $5.0 \mathrm{~mm}$ thick soil protrusion in rough bed condition. The quantities of chemicals per coat estimated to be used for immobilising are given in Table 2. Two separate sprayers was used in applying the chemicals, one for the Sodium Silicate $\left(\mathrm{Na}_{2} \mathrm{SiO}_{3}\right)$ solution and one for the Sodium Bicarbonate $\left(\mathrm{NaHCO}_{3}\right)$ solution. The tank was frozen after draining in order to provide natural geomorphology (Figure $4 \mathrm{~d}$ ). Care was taken to achieve an undisturbed com-
Table 1: Test conditions used in the experiments

\begin{tabular}{ll}
\hline Tested/Measured Parameter & Value/Condition \\
\hline Average grain diameter, $\mathrm{d}_{50}(\mathrm{~mm})$ & $0.15,0.26,0.30$ \\
Soil condition $(-)$ & Wet \\
Soil protrusion, $\mathrm{z}(\mathrm{mm})$ & $1.0-10.0$ \\
Flow discharge, $\mathrm{Q}(\mathrm{l} / \mathrm{s})$ & $1.65-3.57$ \\
\hline
\end{tabular}

pletely frozen sediment bed for better accuracy of results as described by Benson [20].
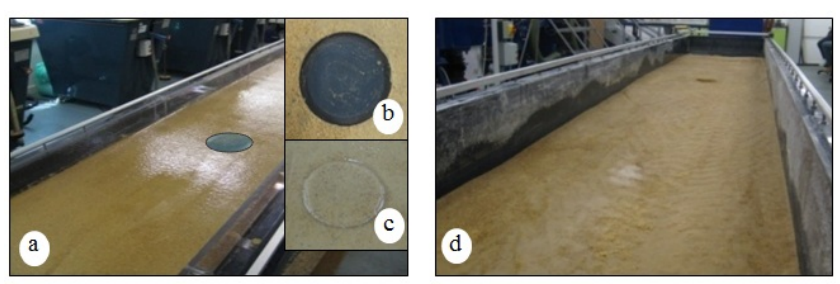

Figure 4: Sediment tank with frozen rough bed.

Table 2: Relative quantities of chemicals used for bed freezing, sufficient to cover $2.4 \mathrm{~m}^{2}(4.0 \mathrm{~m} \times 0.6 \mathrm{~m})$ with one coating.

\begin{tabular}{lll}
\hline & $\begin{array}{l}\text { Sodium Silicate } \\
\text { mixture }\left(\mathrm{Na}_{2} \mathrm{SiO}_{3}\right)\end{array}$ & $\begin{array}{l}\text { Sodium Bicarbonate } \\
\text { mixture }\left(\mathrm{NaHCO}_{3}\right)\end{array}$ \\
\hline $\begin{array}{l}\text { Volume of } \\
\text { chemical }(\mathrm{l})\end{array}$ & 0.33 & - \\
$\begin{array}{l}\text { Mass of } \\
\text { chemical }(\mathrm{kg})\end{array}$ & 0.48 & 0.012 \\
$\begin{array}{l}\text { Volume of } \\
\text { water }(\mathrm{l})\end{array}$ & 0.27 & 0.21 \\
$\begin{array}{l}\text { Approximate } \\
\text { total volume }(\mathrm{l})\end{array}$ & 0.60 & 0.21 \\
\hline
\end{tabular}

\subsection{Soil Properties}

Roundness is a function of abrasion induced by transport and it increases slowly with distance. Sediments need to be transported thousands of miles in a river or sea in order to achieve even moderate rounding [17]. In the present experiments, the images of soil samples taken by Scanning Electron Microscopic (SEM) show that the majority of the sample particles were angular in shape. Figure 5 illustrates the SEM images of tested soil samples while the dimensions of soil particles involved in these experiments 
are presented in Table 3. According to the SEM results, soil sample of $\mathrm{d}_{50}=0.15 \mathrm{~mm}$ was more uniform in shape that of samples of $d_{50}=0.26 \mathrm{~mm}$ and $d_{50}=0.30 \mathrm{~mm}$.

\subsection{Uniformity and Gradation Coefficients}

Soil gradation is an indicator of engineering properties such as compressibility, shear strength, and hydraulic conductivity. The tested soils were a series of uniform sediments of known particle size distributions with known uniformity coefficient sand effective sizes. Apart from the SEM observations, further classification of the experimental soil samples based on the uniformity and gradation coefficients given by Eq. 5 and 6 and the corresponding values are given in Table 4 . The crescent zone phenomenon is described based on this classification, where $C_{u}\left(=d_{60} / d_{10}\right)$ is the uniformity coefficient and $C_{g}\left\{=\left(d_{30}^{2} /\left(d_{10} \times d_{60}\right)\right\}\right.$ is the gradation coefficient [21].

Uniformly graded soil : $C_{u}<3.0$

Well graded soil : $\quad C_{u}>3.0 \& 0.5<C_{g}<2.0$
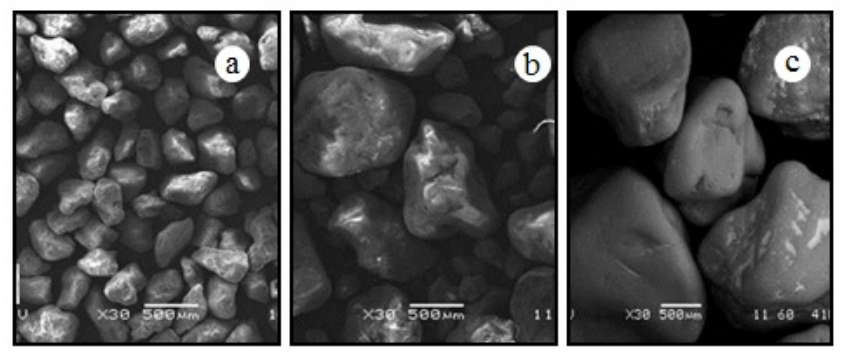

Figure 5: SEM images (a) Well graded soil sample of $d_{50}=0.15 \mathrm{~mm}$, (b) Poorly graded soil sample of $d_{50}=0.26 \mathrm{~mm}$, (c) Poorly graded soil sample of $d_{50}=0.30 \mathrm{~mm}$.

Table 3: Soil particle dimensions measured from SEM

\begin{tabular}{llll}
\hline Sample No & $\mathrm{d}_{50}(\mathrm{~mm})$ & Scale $(\mu \mathrm{m})$ & Dimensions $(\mu \mathrm{m})$ \\
\hline 1 & 0.15 & 500100 & $557 \times 327565 \times 315$ \\
2 & 0.26 & 500200 & $1280 \times 880264 \times 475$ \\
3 & 0.30 & 500 & $2000 \times 2380$ \\
\hline
\end{tabular}

Table 4: Uniformity and gradation coefficients of tested soils

\begin{tabular}{lllc}
\hline Sample No. & $\mathrm{d}_{50}(\mathrm{~mm})$ & $\mathrm{C}_{u}(-)$ & $\mathrm{C}_{g}(-)$ \\
\hline 1 & 0.15 & 1.40 & 1.216 \\
2 & 0.26 & 1.89 & 0.941 \\
3 & 0.30 & 2.16 & 0.867 \\
\hline
\end{tabular}

\subsection{Experimental Procedure}

The general testing procedure that was followed each time of the experiment is as follows:

1. Flow discharge was calibrated ranging from $1.65-$ 3.571/s according to the test conditions.

2. Next soil sample was placed in the SPA tube.

3. The SPA dial was rotated to set the soil protrusion maintaining the dial gauge reading where, $1 \mathrm{com}-$ plete cycle $=1.0 \mathrm{~mm}$ thickness. A manually-operated point gauge was also used to confirm the protrusion height of the sample.

4. The mounted digital video camera was turned on to record sediment movement until the soil sample achieved equilibrium stage and a digital stop watch was used to record the time.

5. The pump was started and observed initiation of sediment movement carefully.

6. The measurements were taken during the flow on the tank bed to calculate the velocity using the Nixon scale.

7. Using a digital still camera the soil sample spreading patterns were captured.

8. A ruler was used to take the longitudinal and lateral spreading lengths of the sample.

9. Using a steel blade an eroded sample was separated maintaining a tangent all the time and finally, the separated sample was collected and stored in a paper envelop.

10. All above steps were repeated for the next test run.

\subsection{Calculation of Erosion Rate}

In this paper, mathematical model considered as a representation of physical system where governing equations are discretised and solved using dimensionless terms. During the investigation, it was in concern to be aware of the conditions and the applicability of such methods. In order to determine the geometrical characteristics of soil erosion, experiments were performed under 2D laboratory controlled unidirectional turbulent flow conditions. 
It is a common practice to divide the mathematical models into different classes according to the dimensionality of the phenomenon involved. Shields [22] applied dimensional analysis and obtained a parameter called Shields function which was plotted against grain Reynolds number. According to the chosen parameters in present experiments, non-dimensional shear stress is in terms of Shields entrainment function. Soil erosion in this study is represented by the dimensionless erosion rate (ER) which is given by,

$$
E R=q_{s t} / d_{50} \sqrt{ }\left(d_{50} g(s-1)\right)
$$

Where $\mathrm{q}_{s t}$ is the volumetric total sediment transport rate per meter width $\left(\mathrm{m}^{2} / \mathrm{s}\right), \mathrm{g}$ is the gravitational acceleration $\left(\mathrm{m} / \mathrm{s}^{2}\right), \mathrm{d}_{50}$ is the median particle size of soil sample $(\mathrm{m})$, $\mathrm{s}$ is the specific density $\left(\rho_{s} / \rho\right), \rho_{s}$ is the density of soil $\left(\mathrm{kg} / \mathrm{m}^{3}\right)$ and $\rho$ is the density of water $\left(\mathrm{kg} / \mathrm{m}^{3}\right)$.

\subsection{Calculation of Shear Stress}

In this analysis, the relationship between shear stress and soil erosion rate was considered in order to analyse and discuss its significance and generality. Shear stress involves in calculation of bed friction factor, velocity and channel geometry (See Eq. 3). Therefore, it was chosen as a governing factor and represented in dimensionless form as,

$$
T=\tau_{s} / \rho g d_{50}(s-1)
$$

Where $\tau_{s}$ is the bed shear stress $\left(\mathrm{N} / \mathrm{m}^{2}\right), \rho$ is the density of water $\left(\mathrm{kg} / \mathrm{m}^{3}\right)$.

\subsection{Calculation of Soil Protrusion}

According to Parker [23], in order to perform a correct accounting of sediment transport, bed level variation, and development of bed stratigraphy, it requires an introduction of a more advanced form of sediment conservation and, in particular, one that is grain-size specific. Hirano [24] introduced a concept that he called the 'exchange layer' which has introduced in this study in an expanded form based on the derivation of top layer investigation of soil hydrodynamics for clear understanding of any river morphology. In this study, the probabilistic nature of fluctuations of bed elevation due to the migration in the form of dunes or bars over a shallow flow plane bed is represented as the soil protrusion parameter (z). During laboratory experiments, it was experienced that erosion rate increases with the increment of soil sample thickness. The dimensionless soil protrusion, $\mathrm{z}$ was represented in this analysis as,

$$
Z=\left(z / d_{50}\right)
$$

where, $\mathrm{z}$ is the thickness (protrusion) of the soil sample (m).

\section{Results and Analysis}

\subsection{Physical Model Studies}

Rivers with poorly-sorted bed sediment create their own stratigraphy as they deposit sediment. Therefore, prediction of the subsequent river degradation into its own deposit requires knowledge of the spatial structure of the grain size variation of the deposits [25]. In recent research studies it was established that bedload sediment transport cannot be understood without considering the major process involved in the hydraulic and bed material conditions governed by erosion. To reveal the causes and consequences of sediment characteristics in fluvial environment, development of a complete physiographic and hydrodynamic conceptual knowledge have prime importance.

In this context, the physics and relevant formulae for erosion of the sediment bed without any obstacles are outlined based on previous research work to understand the behaviour of sediment movement in natural rivers and coastal areas. It is noteworthy to say that, to analyse and explain various interesting phenomena involved in the active layer of soil, experiments were conducted in smooth bed for proper visualisation of the interactive incidences which accordingly conducted into completely frozen rough sediment bed for incorporating the field conditions.

The gradation of soil is a necessary index which represents the engineering properties of soil such as compressibility, shear strength, and hydraulic conductivity [21]. The tested soils were a series of uniform soils of known particle size distributions with known uniformity coefficients and effective sizes. During experiments it was noticed that all the eroded samples showed a deposition pattern which looked like 'crescents'. Figure 6a shows a photographic view of 'crescent' deposition zones for $d_{50}=0.30 \mathrm{~mm}$ wet soil, $\mathrm{z}=5.0 \mathrm{~mm}$ and discharge, $\mathrm{Q}=3.57 \mathrm{l} / \mathrm{s}$. During the rough bed experiments, eroded soil samples were visualised using $\mathrm{KMnO}_{4}$ dye (Figure 6b). Figure 6c shows integrated crescent zones in rough bed experiments for the same soil diameter at equilibrium stage. 

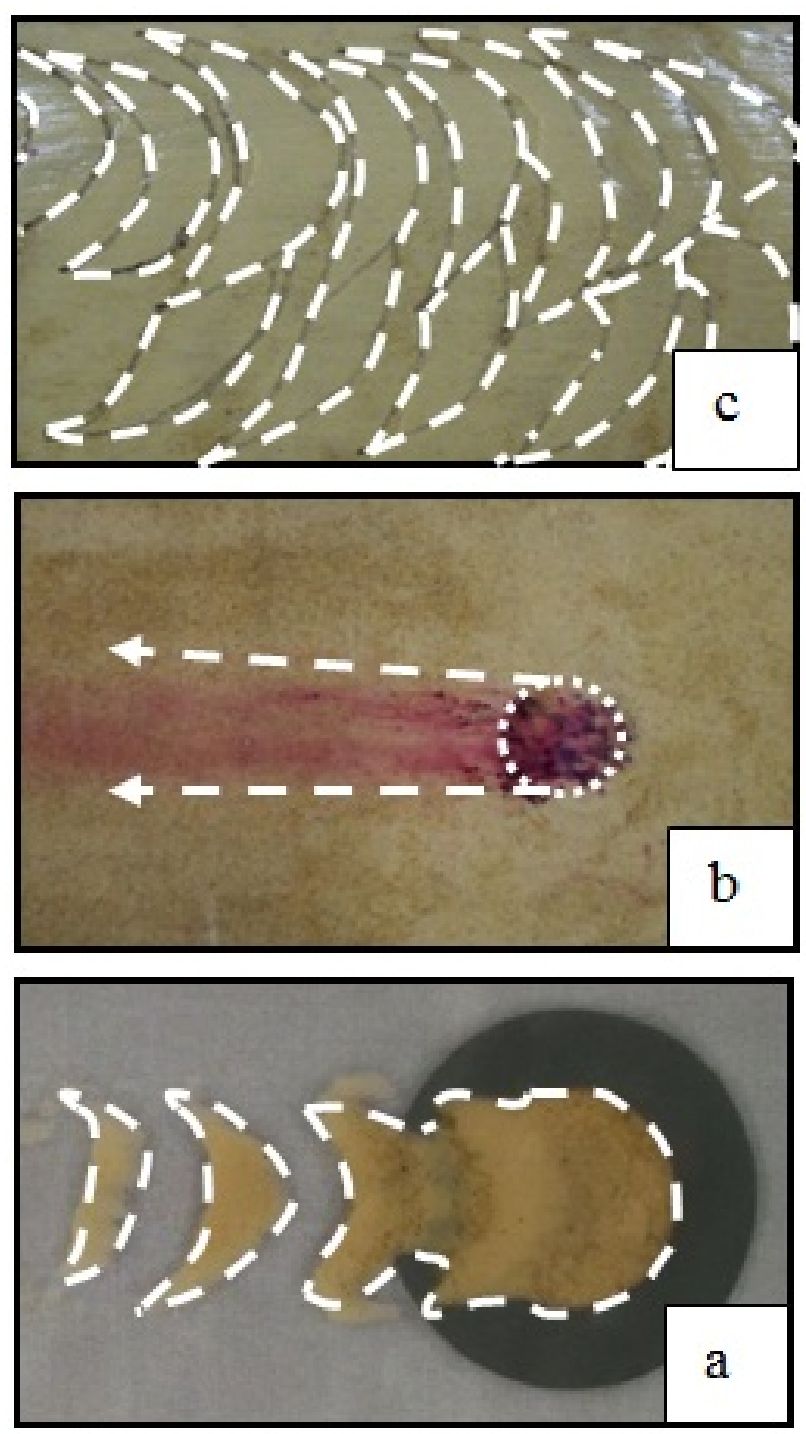

Figure 6: (a) A photographic view of 'crescent' deposition zones (b) Visualised soil sample using $\mathrm{KMnO}_{4}$ dye and (c) Integrated crescent zones in rough bed.

It was observed that irrespective of the gradation of the soil sample, at the long term equilibrium state, the crescent edges were sharper with uniformly graded soil particles. According to the photographic analysis, it was found that the particles achieved the uniformly graded state at equilibrium. Hence, it can be concluded that the erosion pattern was highly dependent on the particle shape and size. If the soil is more poorly graded, the higher the number of 'crescent' zones that are developed. If the sediments are better graded the higher the ability to settle down quickly. Moreover, a sieve analysis of each single crescent for individual experiments revealed that, the $d_{50}$ size of isolated crescent shows a decreasing order as shown in Figure 7 [7].
Figure 8 describes a time dependent analysis of crescent formation. During the erosion process, the crescent zones maintained a sequential order of formation where zone $A$ was first observed then zone $B, C$ and $D$ respectively. Because sediment particles in each crescent zone attempt to settle down as group of same grain sizes .Moreover, the investigation of bed profiles shows when the $d_{50}$ of soil sample is small, the deposition height increases from its sample protrusion that is used in the experiment. This is because the up-lifting of particles of smaller diameter is easier that of the larger sized particles.

\subsection{Empirical Relationships}

The modes of sediment transport in rivers depend on the grain size, shape, density of the material, settling velocity and flow velocity [26]. In the present research project, the area of work and parameters were confirmed after conducting a series of preliminary experiments at UEL Hydraulics Laboratory. Predominant parameters were selected according to their involvedness in the hydrodynamic phenomena as described in earlier sections. Table 5 shows an example of calculation that was followed for all the experimental data obtained.

Finally, a simple empirical relationship was proposed for the dimensionless erosion rate (ER) in terms of Moody shear stress $\left(\tau_{s}\right)$ [16], average sand diameter $\left(\mathrm{d}_{50}\right)$ and soil protrusion ( $\mathrm{z}$ ) using the dimensional analysis and a bestfit technique for smooth bed experiments as described in Jayaratne [8].

$$
\left[q_{s t} / d_{50} \sqrt{ }\left(d_{50} g(s-1)\right)\right]=f\left[\tau_{s} / \rho g d_{50}(s-1),\left(z / d_{50}\right)\right]
$$

or,

$$
\begin{aligned}
& {\left[q_{s t} / d_{50} \sqrt{ }\left(d_{50} g(s-1)\right)\right]=} \\
& 1 \times 10^{-5}\left[\tau_{s} / \rho g d_{50}(s-1)\right]^{0.40}\left[z / d_{50}\right]^{0.21}
\end{aligned}
$$

Within the last decade, several studies reported the use of generalised regression analysis in civil engineering and found them working well in comparison to a best-fit technique approach. The advantage of using a generalized regression analysis is that, it requires few user-defined parameters and provides a better accuracy. The general linear regression model can be written in matrix form as follows:

$$
\underset{(n \times 1)}{Y}=\underset{(n \times p)}{X} \underset{(p \times 1)}{\beta}+\underset{(n \times 1)}{\varepsilon}
$$

Where $Y$ is a vector of responses, $\beta$ is a vector of parameters, $X$ is a matrix of constants and $\varepsilon$ is a vector of errors. 


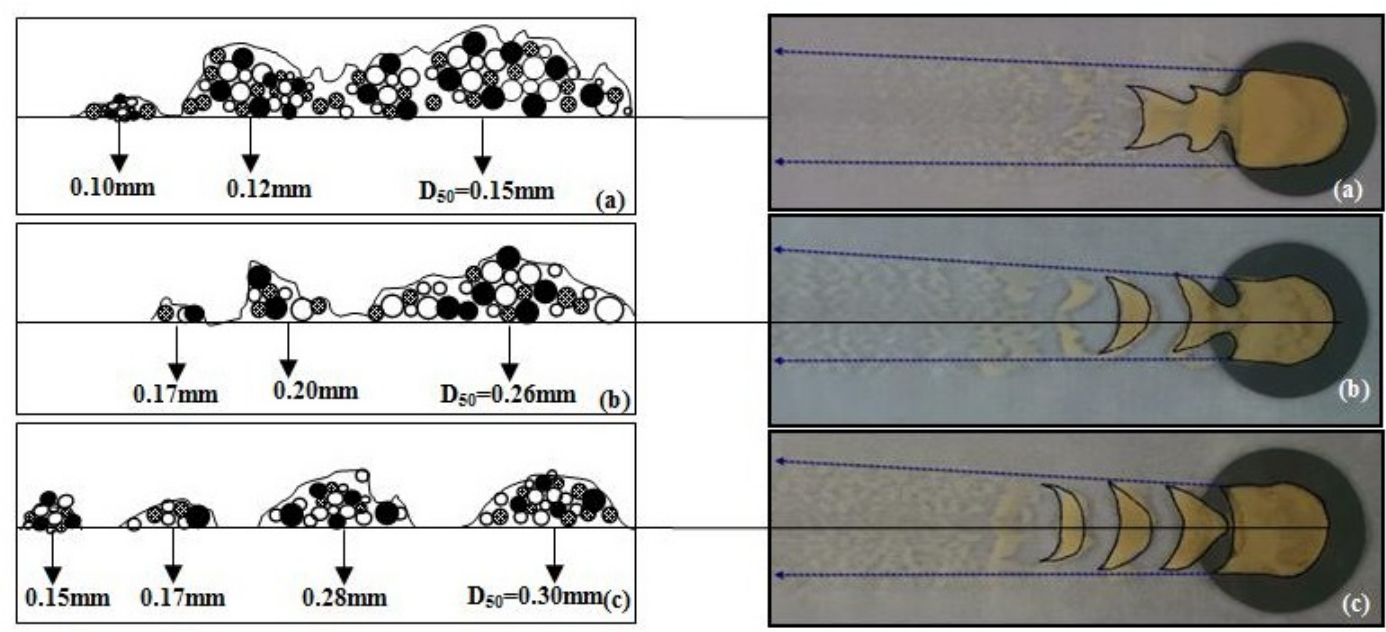

Figure 7: (a) Fixed packing equilibrium settlement of the sample $d_{50}=0.15 \mathrm{~mm}$, (b) Fixed packing equilibrium settlement of the sample $\mathrm{d}_{50}=0.26 \mathrm{~mm}$, (c) Fixed packing equilibrium.

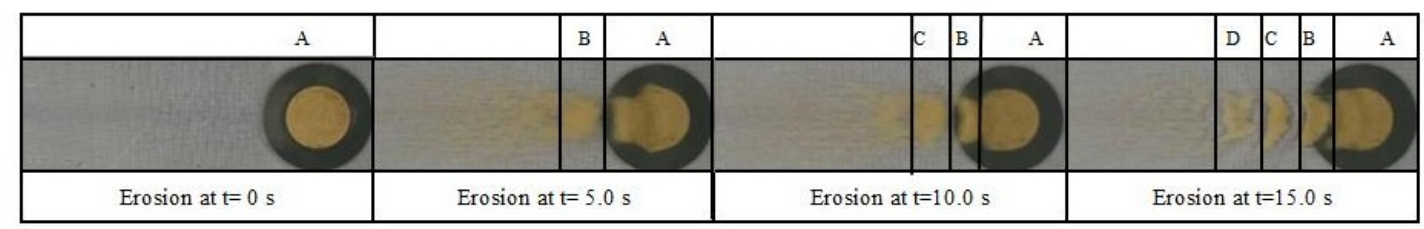

Figure 8: Time-dependent development of crescent zones for $d_{50}=0.30 \mathrm{~mm}$ soil sample with $\mathrm{Q}=3.57 \mathrm{l} / \mathrm{s}$.

By using the least squares method, the values of $\beta$ can be obtained. However, the general linear regression model must satisfy the assumptions that, the mean of $\varepsilon$ is zero, the variance of $\varepsilon$ is constant, the probability distribution of $\varepsilon$ is normal and the random errors are independent.

From Eq. 12 we obtain the original equation as:

$$
\left[q_{s t} / d_{50} \sqrt{ }\left(d_{50} g(s-1)\right)\right]=\beta_{0}\left[\tau_{s} / \rho g d_{50}(s-1)\right]^{\beta 1}\left[z / d_{50}\right]^{\beta 2}
$$

Now Eq. 13 is a form of a multiple linear regression model. Hence, the least squares method was used to estimate the coefficients of Eq. 13 which are $\beta_{0}, \beta_{1}$ and $\beta_{2}$

Assume, $E R=\left[q_{s t} / d_{50} \sqrt{ }\left(d_{50} g(s-1)\right)\right]$,

$T=\left[\tau_{s} / \rho g d_{50}(s-1)\right]$ and $Z=\left[z / d_{50}\right]$

After transforming, $\ln Q=\ln \beta_{0}+\beta_{1} \ln T+\beta_{2} \ln Z$

Using the best equation for smooth bed to predict $q_{s t}$,

$$
\begin{aligned}
& {\left[q_{s t} / d_{50} \sqrt{ }\left(d_{50} g(s-1)\right)\right]=} \\
& 0.0000169\left[\tau_{s} / \rho g d_{50}(s-1)\right]^{0.357}\left[z / d_{50}\right]^{0.192}
\end{aligned}
$$

Where $\mathrm{R}^{2}=0.922$ and quadratic mean, $\bar{R}^{2}=0.919$

The results of regression analysis for smooth bed conditions under three different soil samples is illustrated in
Figure 9. Previously, the same data set was used to propose the empirical relationships in predicting the erosion rate (Eq. 11). A comparison of coefficient of determination and exponent values (Eqs. 11 and 15) indicates that multiple regression based modelling approach provides improved predictions of erosion in comparison to the previously proposed mathematical model $\left(\mathrm{R}^{2}=0.9\right)$.

The data analysis processes for rough sediment bed condition are presented and compared in this paper with the multiple regression model only as the best-fit technique provides less accuracy in prediction of erosion rate as found in the case of smooth bed condition. The predictive model for rough sediment bed was derived as similar manner as in smooth bed condition. It is evident from Figure 10 that, predictions from the regression model using multiple regression analysis for rough bed condition is satisfactory though few records are remarkably exceeding and scattering $\left(R^{2}=0.7\right)$. Performing the similar steps as followed in smooth bed condition, we obtain the best regression equation for rough bed as,

$$
\begin{aligned}
& {\left[q_{s t} / d_{50} \sqrt{ }\left(d_{50} g(s-1)\right)\right]=} \\
& 0.0000169\left[\tau_{s} / \rho g d_{50}(s-1)\right]^{0.383}\left[z / d_{50}\right]^{0.113}
\end{aligned}
$$


Table 5: Sample calculation table for $d_{50}=0.15 \mathrm{~mm}$ soil sample under three different flow discharges

\begin{tabular}{cccccccc}
\hline $\begin{array}{c}\text { Flow } \\
\text { Discharge } \\
(\mathbf{l} / \mathbf{s})\end{array}$ & $\begin{array}{c}\text { Soil } \\
\text { Protrusion } \\
(\mathbf{m m})\end{array}$ & $\begin{array}{c}\text { Settlement } \\
\text { Time } \\
(\mathbf{s})(\mathbf{g})\end{array}$ & $\begin{array}{c}\text { Eroded } \\
\text { Weight }\end{array}$ & $\begin{array}{c}\text { Flow } \\
\text { Velocity } \\
(\mathbf{m} / \mathbf{s})\end{array}$ & $\begin{array}{c}\text { Reynolds } \\
\text { number } \\
\mathbf{R}_{\mathbf{e}}(-)\end{array}$ & $\begin{array}{c}\text { f from } \\
\text { Moody } \\
\text { Diagram }(-)\end{array}$ & $\begin{array}{c}\tau_{\mathbf{s}} \\
\left(\mathbf{N} / \mathbf{m}^{2}\right)\end{array}$ \\
\hline & 5 & 20 & 0.13 & 0.14242 & 12151 & 0.065 & 1648 \\
& 6 & 21 & 0.14 & 0.13889 & 11316 & 0.064 & 1541 \\
1.57 & 7 & 21 & 0.15 & 0.14124 & 11191 & 0.067 & 1674 \\
& 8 & 22 & 0.16 & 0.14007 & 10611 & 0.072 & 1776 \\
& 9 & 23 & 0.17 & 0.13772 & 10305 & 0.079 & 1861 \\
& 10 & 23 & 0.19 & 0.14124 & 15044 & 0.079 & 1968 \\
\hline & 5 & 22 & 0.15 & 0.1636 & 14642 & 0.049 & 1636 \\
& 6 & 25 & 0.17 & 0.1624 & 14642 & 0.053 & 1759 \\
& 7 & 24 & 0.14 & 0.1647 & 14538 & 0.055 & 1852 \\
& 8 & 24 & 0.16 & 0.1647 & 14489 & 0.057 & 1933 \\
& 9 & 21 & 0.16 & 0.1612 & 14329 & 0.063 & 2031 \\
& 10 & 22 & 0.18 & 0.1624 & 14200 & 0.064 & 2107 \\
\hline & 5 & 21 & 0.15 & 0.17412 & 18609 & 0.065 & 2469 \\
& 6 & 23 & 0.16 & 0.17295 & 18198 & 0.056 & 2091 \\
& 7 & 24 & 0.17 & 0.17764 & 17832 & 0.056 & 2201 \\
& 7 & 25 & 0.21 & 0.17530 & 17802 & 0.060 & 2302 \\
& 8 & 23 & 0.19 & 0.17530 & 17596 & 0.062 & 2397 \\
& 9 & 23 & 0.19 & 0.17530 & 17390 & 0.065 & 2485 \\
\hline
\end{tabular}

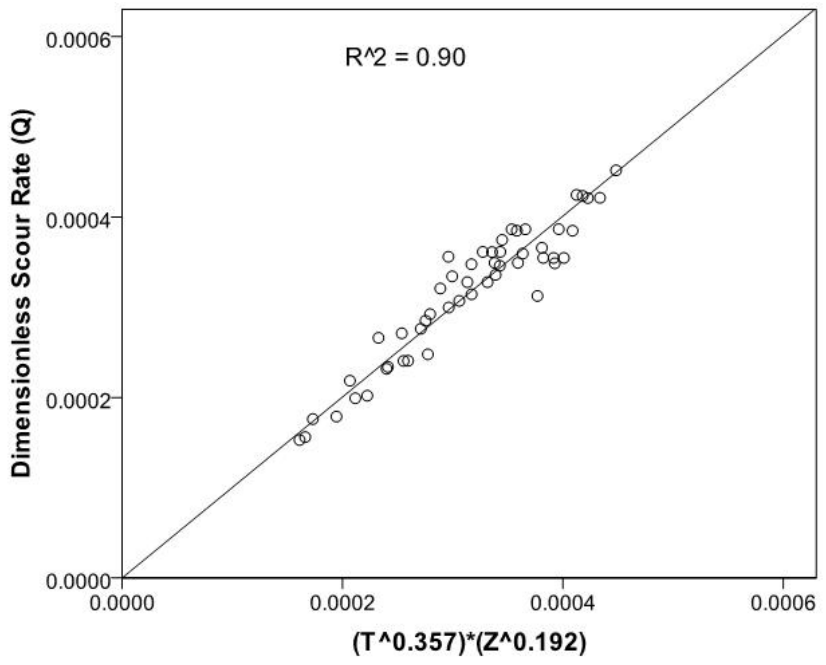

Figure 9: Relationship of dimensionless erosion rate with dimensionless shear stress and soil protrusion for smooth bed condition.

\section{Concluding Remarks}

Present investigation represents an improvement to an initial step taken by the authors, filling the knowledge gap on the fundamental understanding of soil-water interaction in fluvial environment. For this purpose, twelve sets

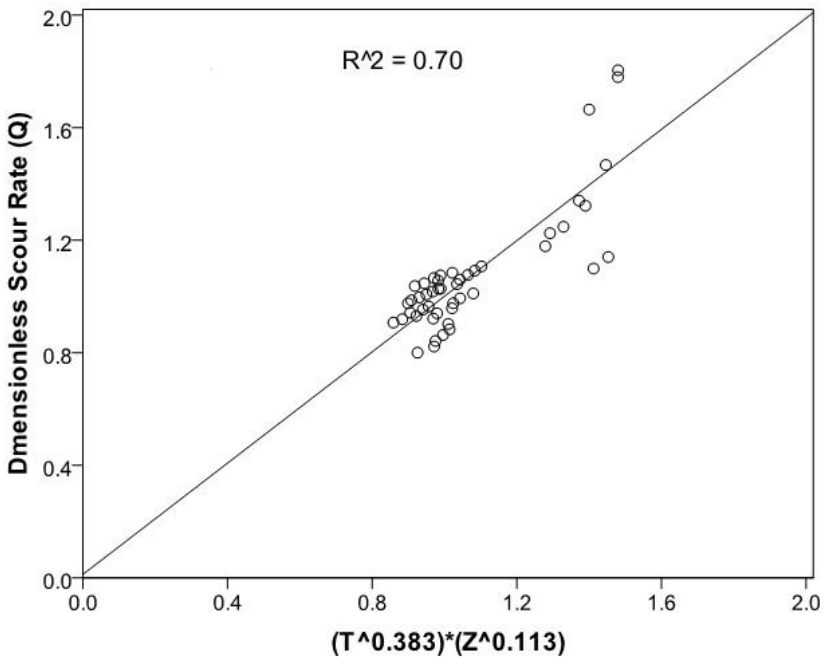

Figure 10: Relationship of dimensionless scour rate with dimensionless share stress and soil protrusion in rough bed.

of small scale 2D laboratory experiments were conducted on two average grain diameters $\left(\mathrm{d}_{50}=0.15,0.26 \mathrm{~mm}\right)$ and five sets of similar experiments were carried out for $\mathrm{d}_{50}=0.30 \mathrm{~mm}$ comprising a total of 330 experiments. The experiments were carried out using a laboratorydeveloped Soil Protrusion Apparatus (SPA) to better un- 
derstanding of fundamental physics of sediment transport and to develop empirical relationships to predict the soil erosion rate per unit width in fluvial environment. Apart from the scale effects, based on the results it was found that for the same flow discharge protruded samples formed crescent zones maintaining a sequential order. For the small grain sized samples, more crescent zones are formed and these are found to be closer to each other compared to the samples with larger grain sizes. It also provides a distinctive comparison of smooth bed erosion condition that of rough bed condition. Further, in the drained sediment tank, integration of crescent zones was observed in rough bed condition which illustrates the similar behaviour of crescent zones described in the smooth bed condition. The empirical relationships were established in terms of smooth and rough sediment bed condition which includes both the general and site-specific erosion rates. As the selection of influential parameters were observed using various physiographic observations, laboratory experimental data of sediment transport rates more accurately represents the relevant physical processes. The empirical relationships, as stated in Eqs. 14 and 15, allow for the specification of processes important in shallow flow transport, including the independent influence of sample protrusion (z). Experiments conducted in uniform flow allowed calibration of a statistically sound model for the flow component of transport capacity [see Eqs. 14 and 15] in which $\mathrm{q}_{s t}$ is dependent on discharge, shear stress and soil protrusion. Particle size was also found to be significant from the present study. Inclusion of an alternative regression method improved the performance of a previously derived empirical equation for erosion rate prediction. The experimental work presented in this paper will be further investigated comparing with full-scale scour measurements such as field data in hydraulic structure failure sites and other well-established formulations in future studies.

Acknowledgement: The authors wish to thank the financial support provided by the Graduate School of University of East London (UEL) to carry out the laboratory experiments in line with the extensive research project "Mathematical and Physical Modelling of Hydrodynamic Erosion of Soils (HES)" set up under first author's "UEL Promising Researcher Fellowship 2009/10”. Special thank goes to Professor D C Wijeyesekera (formerly at UEL) for his pastoral support to initiate the HES project.

\section{References}

[1] McNeil J., Taylor C., and Lick W., Measurements of erosion of undisturbed bottom sediments with depth, Journal of $\mathrm{Hy}$ draulic Engineering, 1996, 122(6), 316-324.

[2] Briaud J. L., Ting F.C.K., Chen H.C., Gudavalli R., Perugu S., and Wei G., Erosion function apparatus for scour rate prediction. Journal of Geotechnical and Geoenvironmental Engineering, ASCE, 2001, 125(1), 105-113, DOI: http://dx.doi.org/10.1061/ (ASCE)1090-0241(2001)127:2(105)).

[3] Roberts J.D., Jepsen R.A., and James S.C., Measurements of sediment erosion and transport with the adjustable shear stress erosion and transport flume. Journal of Hydraulic Engineering, ASCE, 2003, 129(11), 862-871, DOI: 10.1061/(ASCE)0733-9429(2003)129:11(862).

[4] Dietrich W.E., Kirchner J.W., Ikeda H. and Iseya F., Sediment Supply and the development of the coarse surface-layer in gravel-bedded rivers. Nature, 1989, 340(6230), 215-217, DOI: 10.1038/340215a0.

[5] Buffington J.M. and Montgomery D.R., Effects of sediment supply on surface textures of gravel-bed rivers. Water Resources Research, 1999, 35(11), 3523-3530, DOI: 10.1029/1999WR900232

[6] Wilcock P.R., The flow, the bed, and the transport: interaction in flume and field. In: Mosley, M.P. (Ed.), Gravel-Bed Rivers V. New Zealand Hydrological Society Inc, Wellington,2001, pp. 183-220.

[7] Salim S. and Jayaratne R., Studies on hydrodynamic erosion with soil protrusion apparatus, In: Valentine, EM; Apelt, CJ., Ball, J., Chanson, H., Cox, R., Ettema, R., Kuczera, G., Lambert, M., Melville, BW., Sargison, JE. Proceedings of the 34th World Congress of the International Association for HydroEnvironment Research and Engineering, Engineers Australia, Brisbane, 2011, 3761-3768.

[8] Jayaratne R., and Salim S., Shallow Water Hydrodynamic Investigation of Local Scour over Smooth and Rough Sediment Beds, International Journal of Ocean and Climate Systems (IJOCS), Multi-Science, 2012, 229-240, DOI: 10.1260/17593131.3.4.229.

[9] Salim S. and Jayaratne R., Effect of sediment properties on scour rate, Central European Journal of Engineering, Springer Vienna, 2013,3(3). 541-548, DOI: 10.2478/s13531-013-0112-y.

[10] Wilson K., Bed-load transport at high shear stress, Journal of Hydraulic Engineering (Hydraulic Division), 1966, 92 (11), 4959.

[11] Fredsoe J., Deigaard R., Mechanics of coastal sediment transport. Advanced Series on Ocean Engineering, World Scientific Publication, 1994, ISBN: 978-981-02-0840-0.

[12] van Rijn L. C., Sediment transport. Part I: Bed load transport. Journal of Hydraulic Engineering, 1984, 110(10), 1431-1456, DOI: 10.1061/(ASCE)0733-9429(1984)110:10(1431).

[13] van Rijn L. C., Sediment transport. Part II: Suspended load transport. Journal of Hydraulic Engineering, 1984, 110(11), 1613-1641, DOI: 10.1061/(ASCE)07339429(1984)110:11(1613).

[14] van Rijn L. C., Sediment transport, Part III: Bed forms and alluvial roughness, Journal of Hydraulic Engineering, 1984, 110(12), 1733-1754, DOI: 10.1061/(ASCE)07339429(1984)110:12(1733). 
[15] White C.M., The Equilibrium of Grains on the Bed of a Stream. In: Proceedings of the Royal Society of London. Series A. Mathematical and Physical Sciences, 1940, 174(958), 322-338, DOI: 10.1098/rspa.1940.0023.

[16] Moody L.F., Friction factors for pipe flow, Transaction of American Society of Mechanical Engineers, 1944.

[17] van Rijn L.C., Principles of Sediment Transport in Rivers, Estuaries and Coastal Seas, Aqua Publications, Amsterdam, 1993.

[18] Yang C.T., Sediment Transport, Theory and Practice. New York: McGraw-Hill, 1996.

[19] Crowley R.W., Robeck C. and Thieke R.J., Computational Modeling of Bed Material Shear Stress in Piston-Type Erosion Rate Testing Devices. J. Hydraulic Engineering, 2014, 140(1), 24-34.

[20] Benson, I.A., Valentine, E.M., Nalluri, C. and Bathurst, J.C., Stabilising the sediment bed in laboratory flumes. Journal of $\mathrm{Hy}$ draulic Research, 2001, 39(3), 279-282.
[21] Whitlow R., Basic Soils Mechanics, Pearson Prentice Hall, 2001.

[22] Shields A., Application of turbulence research on sediment movement, Communications Press. Hydraulic Engineering And Shipbuilding, Berlin. 1936.

[23] Parker G., Paola C. and Leclair S., Probabilistic Exner sediment continuity equation for mixtures with no active layer. Journal of Hydraulic Engineering, ASCE, 2000, 126(11), 818-826.

[24] Hirano M., River bed degradation with armouring, JSCE, 1971, 195: 55-65 (in Japanese).

[25] Viparelli E., Haydel R., Salvaro M., Wilcock P.R. and Parker G., River morphodynamics with creation/consumption of grain size stratigraphy 1: laboratory experiments. Journal of $\mathrm{Hy}$ draulic Research, 2010, 48(6), 715-726.

[26] Marriot M., Civil Engineering Hydraulics, Wiley-Blackwell Publishers, London, 2009. 